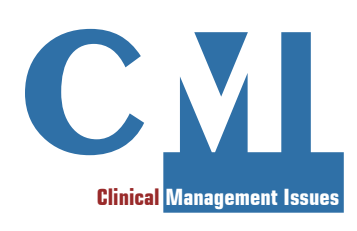

\title{
Menopause and nutraceuticals
}

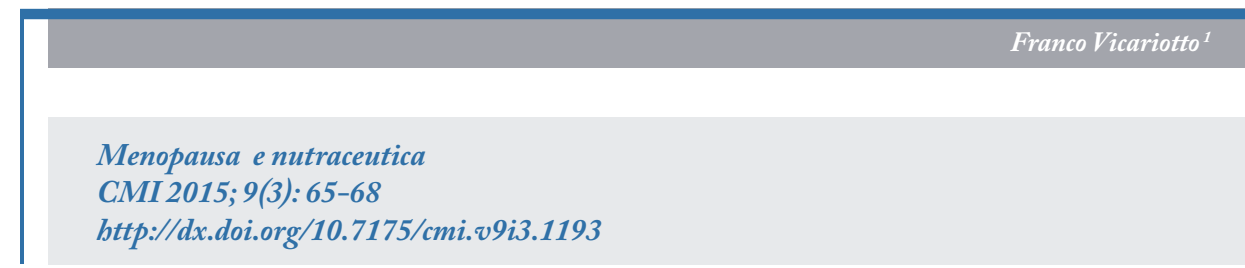

\section{INTRODUCTION}

Definitions of nutraceuticals vary depending on the country legislation. In the European Community, nutraceuticals are generally at the boundary between drugs and food. They are extracted from food or plants with medicinal properties; in general, they are sold in medicinal forms not associated with food [1]. IMS Health defines nutraceuticals as oral unregistered OTC products [2].

Today, instead of being prescribed to healthy subjects, they are generally suggested to reach, maintain, and improve the normal physiological functions in pathological conditions.

According to IMS Health data, far from a crisis, nutraceutical market is growing (now accounting for 2.3 billions/year in Italy).

Along with their specific advantages, nutraceuticals carry also some risks, especially in the absence of clinicians' suggestions, i.e.:

- unknown composition;

- overdosage;

- uncertain origin (sales channels);

- presence of doping and toxic substances;

- side effects;

- drug interactions; and

- lack of diet improvement due to a false sense of security deriving from supplements intake.
A survey involving users of alfemminile. com (a popular Italian forum) showed that women are often the family cornerstone for prevention, healthcare, and supplements purchase [3]. Women purchase $40 \%$ more supplements and botanical remedies than men [4]. Specialists, pharmacists and general practitioners help women most in the choice of the nutraceuticals (accounting for $25 \%, 23 \%$, and $19 \%$, respectively of the suggestions given to women) [3].

Also the web, the suggestions of friends and the advertisements play a role in these choices $(15 \%, 11 \%$, and $7 \%$, respectively) and, together with the fascination with natural products, a false perception of absence of side effects and the possibility of self-medication, are the main determinants of the women's desire of nutraceuticals [3].

Just after pediatricians, gynecologists are the main prescribers of nutraceuticals. Gynecology accounts for 125 million/year of nutraceutical market in Italy [3]; 14\% of gynecologists' prescriptions concern supplements [5]. In the first three months of 2014, menopause accounted for the $12 \%$ of the total gynecology prescriptions (almost half were for pregnancy) [3].

\section{MENOPAUSE}

Life expectancy of women is greater than that of men, and this gap increased from '70s
${ }^{1}$ Gynecologist, Specialist in Obstetrics-Gynecology, SIFIOG (Società Italiana di Fitoterapia e Integratori in Ostetricia e Ginecologia - Italian Society of Phytotherapy and Supplements in Obstetrics and Gynecology)
Corresponding author Franco Vicariotto ginecologia@ vicariotto.com 
Table I. Symptoms/ conditions associated with menopause. Adapted from [7]

\begin{tabular}{|l|l|}
\hline Vasomotor symptoms & $\begin{array}{l}\text { - Hot flushes } \\
\text { - Night sweats } \\
\text { Psychological symptoms }\end{array}$ \\
- Depression \\
- Irritability \\
- Anxiety \\
- Mood swings \\
- Panic attacks \\
- Vaginal dryness and irritation \\
- Reduced libido \\
- Urinary tract infections \\
- Urinary urgency \\
- Painful sexual intercourse \\
Increased bone loss/osteoporosis \\
- Lower back pain \\
- Knee pain \\
- Weakness \\
- Increased risk of fractures \\
- Forgetfulness \\
- Disorientation \\
- Diminished concentrating \\
Metaholic changes
\end{tabular}

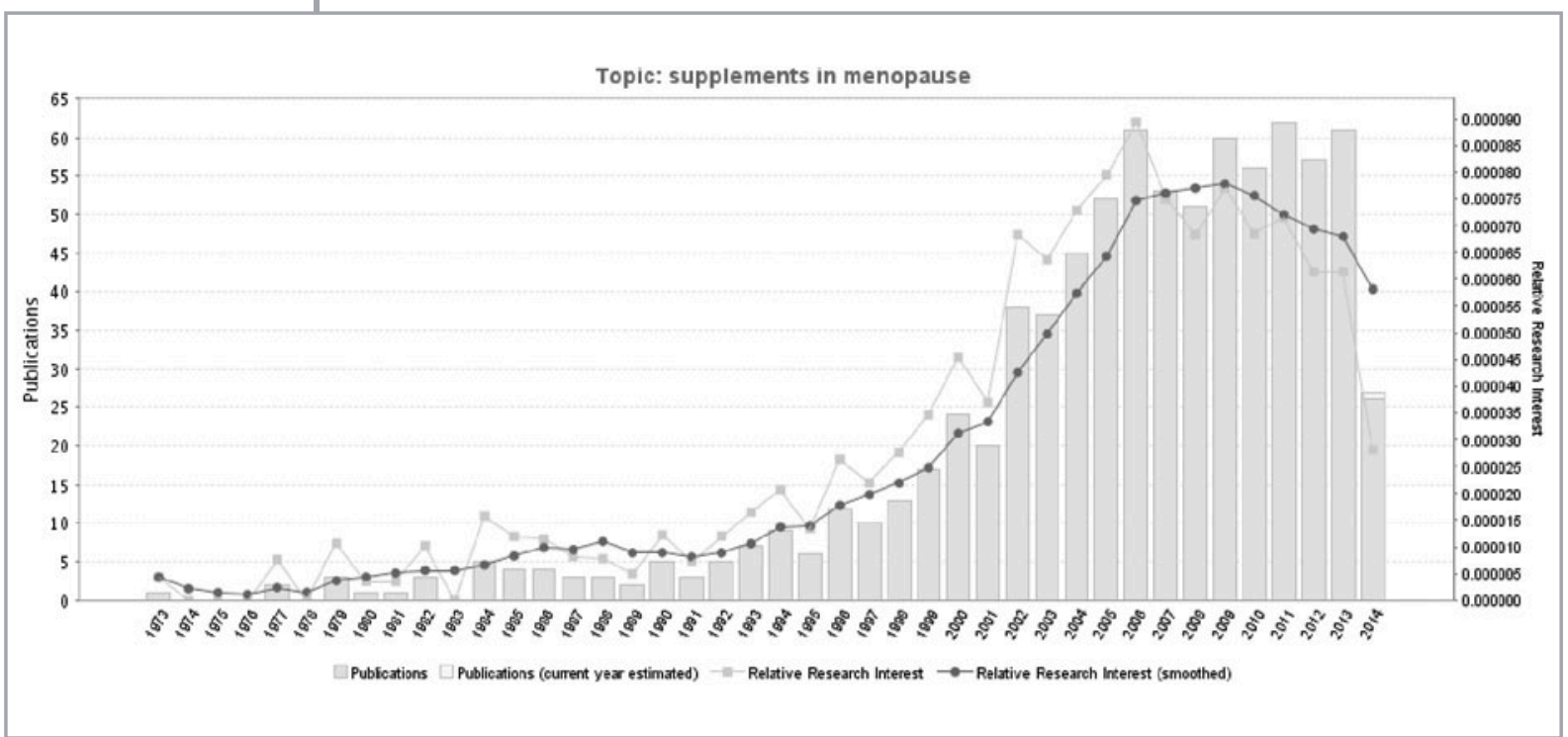

Figure 1. Studies published from 1973 on the topic "supplements in menopause". Histogram created by GoPubMed [10] to 2010 from 4,8 years to 5,7 years. In the meanwhile, also global life expectancy has increased from 61,2 years in 1970 to 73,3 years in 2010 . The main causes of death have generally changed from acute to chronic conditions [6].

Therefore, while life expectancy increased, the quality of life decreased, so that a women 


\begin{tabular}{|c|c|}
\hline Calcium & Reduction in bone loss \\
\hline Plant sterols and stanols & Reduction in LDL- and total cholesterol plasma levels \\
\hline $\begin{array}{l}\text { Vitamin D (in combination with calcium) and } \\
\text { vitamin K }\end{array}$ & Reduction in the incidence of fractures \\
\hline
\end{tabular}

\begin{tabular}{|l|l|}
\hline Hops & Reduction in hot flushes, sweating, insomnia, heart palpitation and irritability \\
Black cohosh & Beneficial effect in early climacteric women \\
St. John's wort & Improvement in menopause-specific quality of life and sleep problems \\
Ginkgo & Significant effect on the test of mental flexibility \\
\hline
\end{tabular}

born in 2010 could expect to live 11 years with chronic conditions or disabilities [6].

Among the symptoms affecting women, there are those due to menopause, that may be highly disabling. During menopause, falling levels of estrogen and progesterone may lead to several symptoms, as reported in Table I.

To restore the pre-menopause physiology, hormone replacement therapy may be used. It is sometimes necessary and very useful, but a long-term administration is contraindicated due to severe long-term side effects that emerged from large trials [8,9], such as increased risk of thromboembolic accidents, stroke and breast cancer. Furthermore, a thorough examination should be preliminarily performed in order to rule out possible pre-existing risk factors contraindicating hormone replacement therapy.

Therefore, attention focused also on alternative therapies.

As reported in Figure 1, numerous studies were carried on in last years concerning the use of supplements in menopause.

\section{NUTRACEUTICALS DURING MENOPAUSE}

A review authored by Borrelli and Ernst [7] analyzed the published literature with the aim of providing an index of reliability on alternative and complementary therapies for menopause.

Here we just focus on supplements and herbal remedies analyzed.

\section{Supplements}

For DHEA (dehydroepiandrosterone), fibers, probiotics and prebiotics, and phytoestrogens, there is no evidence of significant effect on menopausal symptoms or inconsistent or controversial results.

Conversely, calcium, plant sterols and stanols, and vitamins have shown effectiveness in menopause setting (Table II).

\section{Herbal remedies}

Among eight herbal remedies frequently used to alleviate menopause symptoms, four were judged not to be supported by sufficient evidence from literature. They were dong quai, wild yam, ginseng, and evening primrose.

On the contrary hops, black cohosh, St. John's wort, and ginkgo showed to be effective for all or some symptoms they were supposed to alleviate (Table III).

\section{CONCLUSIONS}

The use of nutraceuticals in menopause setting is supported by literature in some, but not all, cases. They can help where drugs fail or are at high risk of severe adverse events.

However, they are to be used with caution and under the supervision of clinicians. In several cases randomized controlled trials are still too few and too incoherent to give a definitive advice.
Table II. Supplements with proved effectiveness in some menopausal symptoms. Adapted from [7]

Table III. Herbal remedies with proven effectiveness in some menopausal symptoms. Adapted from [7] 


\section{REFERENCES}

1. Veling M. Regulatory information resources for nutraceuticals and functional foods: resource guide. (C) 2012 National Research Council of Canada. Available at http://nparc.cisti-icist.nrccnrc.gc.ca/npsi/ctrl?action=rtdoc\&an=19588985\&article=0\&lang=en\&fd=main\&ext=. (last accessed July 2015)

2. Ufficio stampa IMS Health Italia. IMS Health Italia: Nutraceutica - Italia uno dei mercati europei più maturi. Bologna, 17 aprile 2014. Available at http://www.imshealth.com/ (last accessed July 2015)

3. IMS Health Italia. Nutraceutica forum, 2015. Milano, 16 giugno 2015

4. Franconi F, Montilla S, Vella S. Farmacologia di genere. Torino: SEEd Medical Publishers, 2010

5. Ufficio stampa IMS Health Italia. IMS Health Italia: FARMACIA - nei primi due mesi del 2015 il mercato commerciale è cresciuto del 3,7\%. Bologna, 17 aprile 2015. Available at http:// www.imshealth.com/ (last accessed July 2015)

6. AbouZahr C. Progress and challenges in women's health: an analysis of levels and patterns of mortality and morbidity. Contraception 2014; 90: S3-S13; http://dx.doi.org/10.1016/j. contraception.2014.03.007

7. Borrelli F, Ernst E. Alternative and complementary therapies for the menopause. Maturitas 2010; 66: 333-43; http://dx.doi.org/10.1016/j.maturitas.2010.05.010

8. Hulley S, Grady D, Bush T, et al.; for the Heart and Estrogen/progestin Replacement Study (HERS) Research Group. Randomized trial of estrogen plus progestin for secondary prevention of coronary heart disease in postmenopausal women. JAMA 1998; 280: 605-13; http://dx.doi. org/10.1001/jama.280.7.605

9. Writing Group for the Women's Health Initiative Investigators; Rossouw JE, Anderson GL, Prentice RL, et al. Risks and benefits of estrogen plus progestin in healthy postmenopausal women: principal results from the Women's Health Initiative randomized controlled trial.JAMA 2002; 288: 321-33; http://dx.doi.org/10.1001/jama.288.3.321

10. GoPubMed. Available at http://www.gopubmed.org/web/gopubmed/ (last accessed July 2015) 